\title{
Using Real Data in a quantitative methods course to enhance teachers' and school leaders' statistical literacy
}

\section{Manuela Heinz}

National University of Ireland Galway, Ireland

\begin{abstract}
Engaging part-time Master of Education students in the study of quantitative research methods is challenging. The majority of them lead busy lives as teachers and/or education leaders, attend their MEd classes in the evenings and plan to engage in small-scale qualitative research for their theses. In this context, it has been hard to motivate students to engage critically and deeply with quantitative research methods. A widespread deficit view of their own competency in mathematics and computing, which are often considered essential, further compounds the problem. This paper describes the redesign of a quantitative methods module and the resulting changed experiences of students. Findings from this practitioner research study point to the positive impact of using a real national data set - the Growing Up in Ireland Dataset - on students' engagement and appreciation of the value of quantitative research in education.
\end{abstract}

Keywords: Quantitative methods, pedagogy, teacher professional learning, statistics, real data, leadership, literacy, engagement. 


\section{Introduction}

Engaging educators in the study of quantitative research methods is challenging (Smith \& Martinez Moyani, 2012). The majority of our Master of Education students lead busy lives as teachers and/or education leaders, attend their MEd classes in the evenings and plan to engage in small-scale qualitative research for their theses. In this context, I have struggled with the design and delivery of a quantitative research methods module. Our students consistently reported that they considered the module to be difficult and irrelevant to their studies, frequently making reference to their plans of using qualitative methodologies for their thesis research. My repeated explanations regarding the broad aims of our M.Ed. course in relation to training in research skills and the centrality of quantitative research in education never had much of an impact. While students seemed to reluctantly acknowledge that the module formed a core component of the programme and while they (thankfully) also attested to my efforts, enthusiasm and supportive approach, there were only rare moments when I felt that they were captivated and deeply engaged in their learning. More often than not they appeared tired, insecure and, in some cases, resigned to the fact that quantitative methods were too hard and that they were not "great with numbers" - The question of "how relevant is this when I will not be using this methodology?" haunted me the most. How could I make it more relevant?

Reflecting on my own experience with, and on the moments I enjoyed the most when, conducting quantitative research planted the seed for my reconceptualization of the module. Not being a statistician, but rather an education researcher with an interest in using quantitative methods and mixed methods to explore sociological questions related to teaching, learning and schooling; what I enjoyed most was formulating research questions, designing research instruments to collect data and analysing the data. Looking at a new (clean) dataset, running the first statistical tests, experiencing flow, creativity, curiosity and surprise - those were clearly some of my wow moments as a quantitative researcher. Was there a way in which I could transfer this experience into a short introductory quantitative research methods module? Staring with this goal in mind I redesigned the module.

At the core of the redesign was my central effort to use relevant examples from important quantitative education studies throughout - real instruments, real data and real problems and research findings. I wanted to bring about change that is locally appropriate (Somekh \& Zeichner, 2009, cited in Eberhardt \& Heinz, 2016).

\section{Literature review}

Despite a significant increase in the use of data in education at school and national policy levels in Ireland and internationally, and the resulting need for educational leaders to be statistically literate in this 'world awash with numbers' (Sobal, 1981), research focusing on 
how to best prepare educators to engage with quantitative data remains underdeveloped (Salloum, Young, \& Brown, 2016). The most conclusive findings relate closely with my experience; education students, similar to their peers in other disciplines, find quantitative research courses difficult, unpleasant and often unrelated to their own experiences and/or research work (Smith \& Martinez Moyani, 2012; Benson \& Blackman, 2003).

Statistics education is a relatively new area of research (Garfield \& Ben-Zivi, 2007). A number of studies have concentrated on the impact of various pedagogical approaches; for example, Magel (1998) found that cooperative learning approaches used in large lecture contexts led to improved student outcomes. Salloum, Young \& Brown (2016) explored the use of real secondary data in quantitative methods courses designed for doctoral students undertaking research in the field of educational leadership. Their findings are promising, reflecting students' 'favourable support of the use of real data in statistics courses despite challenges to learning statistical software and time constraints inhibiting full engagement in the analyses' (p. 203).

The American Statistical Association's Guidelines for Assessment and Instruction in Statistics Education (GAISE) for teaching introductory college statistics emphasise that the use of real data 'enlivens the class' and furthermore that:

It is important to use real data in teaching statistics to be authentic, to consider issues related to how and why the data were produced or collected, and to relate the analysis to the problem context. Using real data sets of interest to students is also a good way to engage them in thinking about the data and relevant statistical concepts (p. 16).

This paper focuses on the use of secondary data in an introductory quantitative methods module. In preparation for the redesign of the module, permission was sought and granted to use the extensive dataset compiled by the national longitudinal Growing Up in Ireland study, which focuses on the development and education of children in Ireland.

\section{Module Description}

Inspired by my own engagement with national and international student data sets and, in particular, the Growing $U p$ in Ireland $S t u d y^{l}$ I decided to re-design the module and assessment so as to move students to the exciting centre of quantitative research. I was convinced that teachers (many of whom are also parents) had to be interested in the Growing Up in Ireland study, which focuses on the development and education of children in Ireland. I designed a module that allowed me to explore quantitative research methods and results that were of high relevance for teachers in tandem. I wanted students to

\footnotetext{
${ }^{1}$ http://www.esri.ie/growing-up-in-ireland/
} 
scrutinise research findings, raise methodological issues, understand the complexities of quantitative research in the social sciences (including survey design, scale development, reliability and validity issues) and, ultimately, ask and explore their own questions using SPSS and a real national dataset (see extract from worksheet for data analysis workshops in Appendix 1 and samples of slides for this module in Appendix 2).

The core learning outcomes of the redesigned quantitative research module were for students to be able (upon completion of the module) to: critically read quantitative research papers/reports; refine research question/s and select appropriate quantitative methods; design, plan and carry out small-scale quantitative research; conduct basic descriptive and inferential analyses using SPSS; and report findings from basic descriptive and inferential analyses using appropriate terminology and visual representations of data.

Sessions were seminar-based, generally including an input from the lecturer and incorporating small group and whole class discussion.

Growing Up in Ireland is a Government-funded panel study of children carried out jointly by the Economic and Social Research Institute (ESRI) and Trinity College Dublin (TCD). The main aim of the study is to paint a full picture of children in Ireland and how they are developing in the current social, economic and cultural environment. The sample of 8,500 nine-year-old children was randomly selected from 900 schools. In addition, over 2,300 teachers and principals (connected to the study children) cooperated with the study. Children, parents, teachers and principals were surveyed and data sets containing all (coded) data as well as detailed code books, manuals and conceptual frameworks are available for researchers and lecturers on request.

The assessment for this module consisted of: 1) Conducting and reporting on quantitative data analyses (in class collaborative activity using SPSS to analyse Growing Up in Ireland Data) (20 per cent), 2) Review and discussion of a quantitative or mixed methods academic paper (preparation of worksheet and in class activity) (10 per cent), 3) Quantitative methodology paper $(70 \%)$.

\section{Research Methodology}

This practitioner research study set out to explore the impact of using 'real data' in an introductory quantitative research methods module which was part of an MEd programme enrolling mostly teachers, special education teachers and a small number of principals and deputy principals. The overarching research question was: How can I use the Growing Up in Ireland data set to enhance engagement and learning outcomes for my students? Engagement was conceptualized as three-dimensional incorporating behavioural, cognitive and emotional engagement (Fredericks et al., 2004, Keane \& Heinz, 2019). 
Data was collected from MEd students through the use of an end-of-module online questionnaire. Furthermore, students' class work, the questions they posed during class discussions and data analysis workshops as well as their assessments were analysed, and the lecturer recorded notes and reflections after every class.

There were 25 students in the MEd class. Nine of them completed the online questionnaire. All students included a brief reflection on their learning from the quantitative research methods module in their final assessment. Data analysis included frequency statistics and thematic analysis of recurrent themes in the qualitative data.

\section{Findings}

The analysis of the lecturer notes and reflections indicated that student behavioural and emotional engagement was significantly enhanced throughout the module compared to its earlier version which had focused more on the teaching of procedures. The new approach was problem led and the introductory sessions explored different carefully selected education studies employing quantitative research. The problem focused pedagogical approach placed emphasis on understanding the complexities of theoretical constructs like attitudes, motivation, self-concept (see sample slides in Appendix 2) and the challenges associated with measurement. Students engaged critically in discussions about validity of indicators for a wide range of variables (for example social class) and constructs (for example self-concept) and many commented that their 'eyes were opened' and that 'they hadn't thought as deeply about how to measure some of these things' before. Similarly, when introducing simple inferential statistics, the focus on specific and contextually relevant education questions (and questions for which participants typically had hypotheses) resulted in lively discussions (behavioural engagement) and critical questions (cognitive engagement). For example, the question 'whether school type - single sex or mixed - had an impact on girls' maths performance' sparked immediate interest in the study group which contained maths teachers teaching in both, single sex as well as mixed schools. Another, more personal, dimension that I had hoped would further contribute to creating authentic engagement related to the parental perspectives, interests and concerns of many of the mature students'. The use of real-life studies followed by real life data collected and conducted to better understand children's lives and development clearly struck a chord with all participants.

Students' heightened levels of interest were particularly noticeable when they engaged in data analysis. After a review of the GUI child questionnaires which helped to familiarize students with the content of that study and data, and after an introductory workshop to SPSS using common examples, students posed their own questions and conducted simple frequency tests, t-tests and ANOVAS. The topics they chose were wide ranging including 
healthy diet, ways in which parents punish their children for misbehaviour, bullying, children's and parents' perceived body image and breastfeeding. While the late hours and long duration of the workshops scheduled after a full day of work (mostly in the busy school environment) caused a certain level of tiredness for some students they were mostly focused, curious and clearly excited about the tables and graphs they produced with the help of SPSS which gave them the 'real' answer to important questions.

Module evaluations confirmed my own observations and reflections with 100 per cent of respondents $(\mathrm{N}=9)$ confirming that 'the module encouraged critical thinking', that 'the practical workshops provided a good insight into quantitative data analysis', that 'the Growing Up in Ireland data was interesting' and that 'their learning from this module had been meaningful', and eight of nine respondents indicating that 'the practical workshops were enjoyable'.

Table 1.Results.

\begin{tabular}{lccc}
\hline $\begin{array}{l}\text { MEd Quantitative Methodologies Student Feedback } \\
\text { Feedback Survey Item }\end{array}$ & Agree & $\begin{array}{c}\text { Unsure/not } \\
\text { applicable }\end{array}$ & $\begin{array}{c}\text { Dis- } \\
\text { agree }\end{array}$ \\
\hline $\begin{array}{l}\text { The expected outcomes of the module were clear to me. } \\
\text { The module was well organized. }\end{array}$ & 9 & 1 & 0 \\
The module encouraged critical thinking & 9 & 0 & 0 \\
The practical workshops were enjoyable & 8 & 1 & 0 \\
$\begin{array}{l}\text { The practical workshops provided a good insight into } \\
\text { quantitative data analysis }\end{array}$ & 9 & 0 & 0 \\
$\begin{array}{l}\text { Working with Growing Up in Ireland data was } \\
\text { interesting }\end{array}$ & 9 & 0 & 0 \\
$\begin{array}{l}\text { Overall I feel that my learning from this module has } \\
\text { been meaningful }\end{array}$ & 9 & 0 & 0 \\
\hline
\end{tabular}

\section{Conclusion}

The findings from this study indicate that the use of real data in conjunction with active and problem-based learning methodologies can positively impact the engagement of part-time Master of Education students who are also education professionals. As illustrated by the student quote below, the practical approach and relevance of chosen problems and materials helped many students to overcome deficit views regarding their numerical and computing abilities which have been identified as common and serious barriers to learning on quantitative research modules (Acton and McCreight, 2014, 9).

As I reflect on the quantitative research module I realise how much I have learned, despite my struggles with the content. Looking back [...], I realise that initially my 
attitudes [...] were very much influenced by my own self-perception as a learner, as being inadequate in my numerical and computing abilities.

Nonetheless, the module enabled me to gain a deeper insight into a range of quantitative methodologies [...]. I learned about research design, sampling, data collection and data analysis involved in quantitative research. I was introduced to statistics, particularly as they are used in educational research. I learned about SPSS, and how it is widely used for quantitative data analysis in education and the social sciences. But the most significant change for me was that I became more confident in my understanding and ability to critically read quantitative research papers and reports, especially through completing the assignments.

So what are the implications of this to my own professional practice? I have seen that sometimes it is useful to make certain areas of study obligatory. I have also seen the positive impact of these [active and hands on] learning strategies when used in areas of weakness. I will therefore try to incorporate these lessons into my own professional practice [as a teacher].

\section{References}

Acton, C., \& McCreight, B. (2014). Engaging students in quantitative research methods: An evaluation of Assessment for Learning strategies on an undergraduate social research methods module.

Benson, A., \& Blackman, D. (2003). Can research methods ever be interesting?. Active learning in higher education, 4(1), 39-55.

Eberhardt, A., \& Heinz, M. (2017). Walk little, look lots: Tuning into teachers' action research rhythm. Studying Teacher Education, 13(1), 36-51.

Fredricks, J. A., Blumenfeld, P. C., \& Paris, A. H. (2004). School engagement: Potential of the concept, state of the evidence. Review of educational research, 74(1), 59-109.

Garfield, J., \& Ben-Zvi, D. (2008). Developing students' statistical reasoning: Connecting research and teaching practice. Springer Science \& Business Media.

Keane, G., \& Heinz, M. (2019). Differentiated homework: Impact on student engagement. Journal of Practitioner Research, 4(2), 1.

Magel, R. C. (1998). Using cooperative learning in a large introductory statistics class. Journal of Statistics Education, 6(3).

Salloum, S. J., Young, T. V., \& Brown, R. D. Teaching Introductory Quantitative Research Methods to Doctoral Students in Educational Leadership: Using Real Data to Improve Statistical Literacy.

Smith, A. E., \& Martinez-Moyano, I. J. (2012). Techniques in teaching statistics: Linking research production and research use. Journal of Public Affairs Education, 18(1), 107136.

Sobal, J. (1981). Teaching with secondary data. Teaching Sociology, 149-170. 


\section{Appendix 1. Extract from Practical Workshop - Interrogating Growing up In Ireland data}

Below are sample research questions that were explored through analysis of GUI data. The relevant Variable Labels are indicated in brackets behind the research questions.

A) We want to study the phenomenon of bullying.

1) Descriptive statistics - describing the data - occurrence and perceived reasons for bullying, feelings of children who were bullied and rates of reporting of bullying
a. What percentage of children report that they have been bullied? (Q42.)
b. How often do children report the bullying took place? (Q43.)
c. What form did the bullying take? (percentage of children reporting bullying incidents falling into different categories) (Q44A.-I.)
d. What do children perceive to be the reasons for being bullied? (Q45A.-K.)
e. How did children who were bullied feel? (Q46. (a)-(g)
f. Did children tell anyone that they were bullied? Who did they tell? (Q47. \& Q48a.-d.)

2) Inferential statistics - exploring/testing relationships
a. Do children's reports of being bullied correlate with primary caregiver's reports of their child being bullied (do PCG know about their children's difficulties)?
(Q42. \& E11.) - cross-tabulation / chi-square test
b. Is there a correlation between being bullied (yes/no) and children's self- concept (Piers Harris Scores)?
(Q42. \& Piers Harris_Totalscore etc.) - independent sample t-test

B) We want to study the phenomenon of parenting

1) Descriptive statistics - describing the data

a. When children misbehave, what methods do parents use to discipline them? (Q59. (a) - (i))

b. How well do children get on with their mum? (1. How well...)

c. How well do children get on with their dad? (2. How well...)

d. How well do children get on with mum's partner? (3. How well...)

2) Inferential Statistics - exploring/testing relationships

a. Is there a statistically significant gender difference? Is there a statistically significant difference with regard to the disciplining methods used by parents with girls and boys? (Person 2 gender \& Q59. (a) - (i) - cross-tabulations / chi-square tests

b. Is there a statistically significant difference by social class? Do children from different social class backgrounds experience different parental disciplining methods? (Family's social class \& Q59. (a) - (i)- cross-tabulations / chisquare tests 
c. Is there a statistically significant relationship between parental disciplining methods and children's self-concept (Q59. (a) - (i) \& Piers Harris_Total Score)? - ANOVAs

d. Is there a statistically significant relationship between the level of parental involvement in school and children's school performance/ability as measured by Drumcondra Tests?(P38b \& Drumcondra Total Score test) - ANOVAs

C) We want to study predictors of self-image

1) Descriptive statistics - describing the data

a. Check means and distribution for the Piers Harris Self-Image Scores - are they normally distributed? (Piers Harris_Totalscore, etc.)

2) Inferential Statistics - exploring/testing relationships

a. Is there a statistically significant gender difference? Is there a significant difference between the mean scores of boys and girls? (Person 2 gender \& Piers Harris) independent sample t-test

b. Is there a statistically significant social class difference? Is there a statistically significant difference between the self-image scores of children from different social class backgrounds? (Family's social class \& Piers Harris) ANOVA

c. Do children who like school have a more positive self-image? (Q5x \& Piers Harris) ANOVA

\section{Appendix 2: Sample Slides from Quant Methods Module}

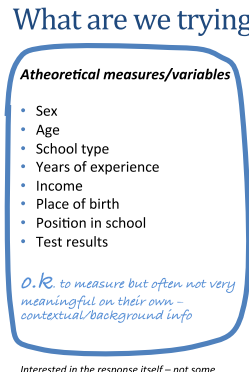

Interested in the response itself-not some
characcteristic that it is thought to represent

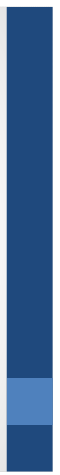

Validated Scale Example 1

The Forms of Bullying Scale

(Shaw, Dooley, Cross, Zubrick, Waters, 2013)

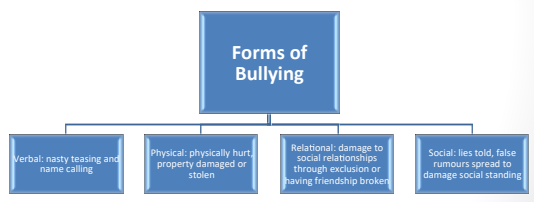


Validated Scale - Practice Example

Student-teacher relationship scale

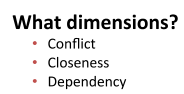

Closeness

- Dependency

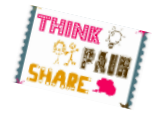

Develop items - statements that can be rated according to agreement

Example: I share an affectionate, warm relationship with this child.

See scale in "Measuring theoretical constructs - scales" folder on $\mathrm{Bb}$ See more info and links to scales and relevant articles at:
http://curry.virginia.edu/about/directory/robert-c.-pianta/measures

\section{Topics explored in GUI}

- Child's Birth

- Household Composition

- Child's Health/Healthcare

- Child's Cognitive Development

- Child's Nutrition

- Child's Relationships

- Child's Lifestyle (Habits, Play, Activities)

- Child's Physical Activity Levels / Exercise

- Childcare Arrangements

- Child's Education / Home Learning Environment

- Child's Physical Development

- Child's Socio-emotional Development (Wellbeing)
Example of research problem 1: Academic Performance and Single-Sex Schooling

- Does school type - single sex or co-ed - have an impact on the maths performance of girls?

Does school type-single sex or co-ed - have an impact on the language performance of girls?

What are the independent and dependent variables? What other variables might be intervening or moderating the relationship? Should we control for any variables?

(see study by Eisenkopf et al., 2015) This is were theory comes into quant research: Researcher uses previous findings
to develop Theory - a scientific prediction or explanation for what s/he expects to to develop theory - a scientific prediction or explanation for what s/he expects to
find $O R$ a set of interrelated constructs (variables), definitions, and propositions that presents a systematic view of phenomena by specifying relations amon (see Creswell, 2014, 537, 60f., Kerlinger, 1979, Thomas, 1997)
(1)

Some examples from your analyses

\section{Perceptions of school and self-concept}

Perception of school experience: ANOVA test indicated a significant linear relationship between children's perception of school and between children's perception of school and
their positive self-image as measured by Piers their positive self-image as measured by
Harris (total score). With regard to the children's total self-image PIERS Harris scores, mean scores were lowest for children who hated school ( $M=37.31 \mathrm{SD}=10.21$ ) and highest for children who liked school very much $(M=50.87 \mathrm{SD}=6.48) .(\mathrm{F}(4,7320)=279.084 p=$ $.0000)$

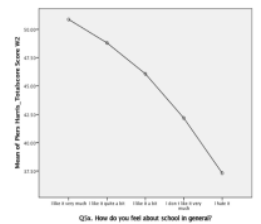

